Landslides (2015) 12:293

DOI 10.1007/s10346-014-0525-6

Published online: 3 October 2014

(c) Springer-Verlag Berlin Heidelberg 2014

Franny Giselle Murillo-García · Irasema Alcántara-Ayala · Francesca Ardizzone ·

Mauro Cardinali · Federica Fiorucci · Fausto Guzzetti

\title{
Erratum to: Satellite stereoscopic pair images of very high resolution: a step forward for the development of landslide inventories
}

Erratum to: Landslides

DOI 10.1007/s10346-014-0473-1

The original version of this article, unfortunately, contained an error.

Federica Fiorucci's surname was incorrectly spelled as "Fiourucci". The correct spelling is now given in this article.

The online version of the original article can be found at http://dx.doi.org/10.1007/ s10346-014-0473-1.

F. G. Murillo-García (- ) I. Alcántara-Ayala Universidad Nacional Autónoma de México,

Mexico, D.F., Mexico

e-mail: fran.79v@gmail.com

F. Ardizzone - M. Cardinali · F. Fiorucci · F. Guzzetti Istituto di Ricerca per la Protezione Idrogeologica (CNR-IRPI),

Via Madonna Alta 126, 06128, Perugia, Italy 